\title{
The Growth, Ageing and Urbanisation of our World
}

\author{
George W. Leeson ${ }^{1}$
}

Published online: 29 May 2018

(C) Springer Science+Business Media B.V., part of Springer Nature 2018

The world is ageing - both at an individual and population level - and this ageing produces challenges and opportunities for governments and citizens across the globe (Leeson and Harper, 2006, 2007a, b and c, 2008). In addition, the world is also becoming increasingly urbanised with more and more people living in urban settings. In 1950, 70\% of people globally lived in rural settlements and just $30 \%$ in urban settlements. By 2014, 54\% of the world's population lived in urban settings and the urban population of the world is expected to continue to grow, so that by $2050,66 \%$ of the world's almost 10 billion inhabitants will be urban dwellers (United Nations 2014).

As far as individual ageing is concerned, globally, life expectancies at birth have increased from 47 years in the mid-twentieth century to around 71 years today, and are expected to rise to around 78 years by the mid-twenty-first century. As far as population ageing is concerned, the proportion of the world's population aged 60 years and over has increased from 200 million and $8 \%$ of world population in the mid-twentieth century to almost 1 billion and $12 \%$, and by 2050, it is expected to reach $21 \%$ and around 2.1 billion people (United Nations 2017). This ageing is, however, not uniform across the world, nor is it uniform across regions of the world or even within countries of the world, and the individual experience of ageing as well as the societal response to ageing are diverse, giving rise to striking inequalities in many cases.

Nor is urbanisation uniform across the world. In 2014, the most urbanized regions were North America (82\% living in urban areas), Latin America and the Caribbean (80\%), and Europe (73\%), while Africa and Asia still just remained mostly rural, with 40 and $48 \%$ of their respective populations living in urban areas. All regions of the world will continue to urbanize with the most rural regions of Africa and Asia urbanizing faster than elsewhere - their urban populations reaching 56 and $64 \%$ of their total populations, respectively, by 2050 . Although the share of the global

George W. Leeson

eorge.leeson@ageging.ox.ac.uk

1 Oxford Institute of Population Ageing, Kellogg College \& Oxford Martin School, University of Oxford, Oxford, UK 
population living in rural areas has declined, the absolute size of the global rural community has grown and is expected to peak in the near future (United Nations 2014). Currently, the global rural community amounts to almost 3.4 billion people. This is expected to decline to 3.2 billion people by the middle of the twenty-first century. In addition to being the least urbanised continents of the world, Africa and Asia are also home to almost $90 \%$ of the world's total rural dwellers but as far as individual countries are concerned, India has the largest rural population ( 857 million), followed by China (635 million).

The global urban community has increased in size almost five-fold from 746 million in 1950 to 3.9 billion in 2014. Asia has modest levels of urbanization as a region, but it is home to $53 \%$ of the world's urban community. This compares with Europe's 14\% and Latin America and the Caribbean's 13\%. Population growth and urbanization are predicted to continue into the twenty-first century, bringing an additional 2.5 billion people to the world's urban community by 2050 , with nearly $90 \%$ of this concentrated in Asia and Africa. Strikingly, three countries alone - namely India, China and Nigeria - are together predicted to account for $37 \%$ of this projected growth in the world's urban community between 2014 and 2050, with India adding 404 million urban dwellers, China 292 million and Nigeria 212 million.

From 1950 to 1987 , global population doubled from 2.5 to 5 billion and by 2050 it is expected to have almost doubled again to 9.8 billion (United Nations 2017). In 1950, $55 \%$ (1.4 billion people) of the world's population lived in Asia, 22\% (549 million people) in Europe, 9\% (229 million people) in Africa, around 7\% (approximately 170 million people) in both Northern America and Latin America and the Caribbean and less than 1\% (13 million people) in Oceania. By 2015, the world order in terms of population had changed. The largest proportion - 60\% - still lives in Asia (4.4 billion), but Africa with $16 \%$ (1.2 billion) is the now the second most populous region of the world, followed by Europe (10\% and 741 million), Latin America and the Caribbean (almost 9\% and 632 million), with the remaining 5\% in Northern America (356 million) and Oceania (40 million).

\section{Population Growth and Urbanisation}

\section{Population Growth Differs from Region to Region around the World}

Latin America and the Caribbean experienced population growth rates as high as $2.8 \%$ per annum in the early 1960s, which were the highest rates of growth in any region of the world. Such high growth rates resulted from a combination of declining levels of mortality and high levels of fertility at almost 6 live births per female on average (Leeson 2013). However, by 1990-1995, total fertility in the region had fallen to 3.01 and continued to decline. Even so, over 30 years, population size doubled from 221 million in 1960 to 447 million in 1990, and it continued to grow, reaching 632 million in 2015 (United Nations 2017). This continued growth even with declining fertility was partly because the large birth cohorts of the high fertility era produced large numbers of births despite their lower average fertility and partly because decreasing mortality meant that more and more people survived to older ages (life expectancy at birth for both sexes combined increased by more than 20 years from 51.2 years in 1950-1955 to 
74.6 years in 2010-2015) and significantly more children were surviving their first year of life (infant mortality rates fell from 128 per 1000 live births in 1950-1955 to 19 per 1000 live births in 2010-2015). Thus, by 2015, despite the level of fertility in the region falling to 2.14 per female, the population of the region had reached 632 million and $8.5 \%$ of global population. In other words, in just 65 years, the population of the region had almost quadrupled. In this same period, the region was becoming more urbanised. In the mid-twentieth century, around $41 \%$ of the region's population lived in urban settings, and by 2015 this had doubled, with $80 \%$ now living in urban settings. The region's urban community is expected to comprise $86 \%$ of its total population by 2050 (United Nations 2014). At the beginning of the 1950s, the size of the region's population was more or less the same as that of Northern America (Canada and the United States), but 60 years on the North was demographically overshadowed by its southern neighbours by more than 250 million people. The medium variant of the United Nations Population Forecasts suggests that the population of Latin America and the Caribbean will continue to grow despite fertility levels dropping even further to 1.76 , reaching 780 million and $8 \%$ of the total world population by 2050 , outpopulating its northern neighbours by almost 350 million by that time.

In Asia in the 1950s, growth in the region was around $1.9 \%$ per annum, increasing to almost $2.5 \%$ in the late $1960 \mathrm{~s}$, after which there was a more or less continued decline to 1.05 by 2010-15 (United Nations 2017). Levels of fertility in the region were also relatively high - more than 5 until the mid-1970s after which levels declined steadily to just 2.2 by $2010-15$. Once again, despite declining levels of fertility, the region's population tripled in size from around 1.4 billion in 1950 to 4.4 billion in 2015 (United Nations 2017). In the early 1950s, life expectancy at birth for both sexes combined in Asia was lower than in Latin America and the Caribbean standing at 42.3 years, but by $2010-15$, it had almost caught up with life expectancy in Latin America and the Caribbean having increased by almost 30 years to 71.8 years. As in Latin America and the Caribbean, infant mortality rates fell significantly from 157 per 1000 live births in 1950-1955 to 31 per 1000 live births in 2010-2015 but they remain higher than in Latin America and the Caribbean. So, by 2015, despite continued declines of fertility to 2.2 per female, the population of the region had reached 4.4 billion and $60 \%$ of global population and from 1950 to 2015, the region's population had more than tripled. Asia too in this period has become more urbanised. In the midtwentieth century, around $18 \%$ of the region's population lived in urban settings, and by 2015 this had more than doubled to $48 \%$ now living in urban settings, and it is expected to increase to around $64 \%$ in 2050 . The medium variant of the United Nations Population Forecasts expects the population of this, the world's most populous region to reach 5.3 billion and $54 \%$ of total world population by the middle of the twenty-first century.

Population growth in Africa in the early 1950s in the region as a whole was on a par with growth in Asia, amounting to around $2.1 \%$ per annum. For the whole continent, growth rates increased steadily to around $2.8 \%$ per annum in $1980-85$ before beginning a decline to 2.46 at the end of the twentieth century. However, the twenty-first century has seen African growth rates almost attain those peak 1980s' levels with a growth rate of 2.6\% in 2010-15 (United Nations 2017). Growth for the continent remains relatively high, driven by some of the world's highest levels of fertility. Fertility was high in the early 1950s - almost 7 live births per female and did not fall below 5 until the 
beginning of the twenty-first century, reaching 4.7 by $2010-15$, still the highest of the World's continents, and with several countries still experiencing fertility levels in excess of 6, for example Burundi (6), DRC (6.4), Chad (6.3), Mali (6.3), Somalia (6.6) and Niger even higher at 7.4. These consistently high levels of fertility mean that the region's population increased from 229 million in 1950 to almost 1.2 billion in 2015 (United Nations 2017). Part of the increase is of course due to decreasing mortality. In the early 1950s, life expectancy at birth for both sexes combined in Africa was the lowest of the world's continents at just 37.5 but by 2010-15, it had increased by more than 20 years to 60.2 years, still easily lower than the other continents as a whole. In Africa too, infant mortality rates fell significantly post 2nd World War from 188 per 1000 live births in 1950-1955 to 57 per 1000 live births in 2010-2015. In this same post war period, Africa had also become more urbanised. In the mid-twentieth century, around $15 \%$ of the region's population lived in urban settings, and by 2015 this had almost tripled to $40 \%$ now living in urban settings, the expectation being around $56 \%$ in 2050. According to the medium variant of the United Nations Population Forecasts, the population of the world's high fertility region will continue to grow, reaching 2.5 billion and $25 \%$ of total world population by 2050 . However, if fertility in Africa remains at current levels, the continent's population in 2050 will stand at 3.2 billion rather than 2.5 billion, and in 2100 it would reach a staggering 16.3 billion rather than the 4.5 billion under the medium variant scenario.

Population growth in Northern America in the early 1950s was lower than growth in Asia and Africa, amounting to around $1.75 \%$ per annum. Rates declined to less than $1 \%$ per annum by the 1980 s before increasing towards the end of the twentieth century. However, the twenty-first century has seen Northern American growth rates decline again to just $0.75 \%$ (United Nations 2017). Northern American has experienced levels of fertility at or below replacement levels since the early 1970s having fallen from the levels in the 1950s and early 1960s of around 3.5 live births per female. However, the region's population doubled in size from 173 million in 1950 to 356 million in 2015 (United Nations 2017). Much of this increase is due to international migration with net migration rates as high as 6.2 per 1000 population in the 1990s. Declining mortality has also played a role of course. In the early 1950s, life expectancy at birth for both sexes combined in Northern America was the highest of the world's continents at 68.7 years. By 2010-15, it had increased by more than 10 years to 79.2 years, but now comparable to life expectancies in much of the world outside Africa, parts of Eastern Europe and some parts of Asia. Even here in one of the world's longest-lived continents, significantly more children were surviving their first year of life. Infant mortality rates fell from 31 per 1000 live births in 1950-1955 to just 6 per 1000 live births in 2010-2015 at both points in time among the lowest infant mortality rates in the world. So, in 65 years, from 1950 to 2015, the population of the Northern American region has doubled and over this same period, the region has also become more urbanised. In the mid-twentieth century, around $64 \%$ of the total population in the region lived in urban settings, and by 2015 this had risen to $82 \%$, the expectation being around $87 \%$ in 2050 . The medium variant of the United Nations Population Forecasts suggests that the population of Northern America will continue to grow, reaching 435 million but declining in relative terms to $4.4 \%$ of total world population by 2050 .

In the 1950s, Europe had the world's lowest population growth rate, amounting to $0.98 \%$ per annum. Growth rates declined steadily towards the end of the twentieth 
century, actually becoming negative at $-0.02 \%$ in $1995-2000$. The first 15 years of the twenty-first century have seen European growth rates again become positive, but only just at $0.1 \%$ in 2010-15 (United Nations 2017).

European population growth has thus been consistently low throughout the second half of the twentieth century and the early twenty-first century, driven in part by low levels of fertility. In the 1950s, fertility levels were around 2.7 live births per female, after which they declined to a European low of 1.43 in 2000-05 when in fact no European country had an above-replacement level of fertility. European fertility has shown signs of recovery, reaching 1.6 by $2010-15$. The region's population as a consequence has increased modestly from 549 million in 1950 to 740 million in 2015 (United Nations 2017). The increase in European population size has also been driven by international migration with net migration rates ranging from 0.5 to 2.3 per 1000 population, and by declining mortality. In the early 1950 s, life expectancy at birth for both sexes combined in Europe was 63.6 years. By 2010-15, life expectancy had increased by almost 14 years to 77.2 years (and in excess of 80 years in a large number of European countries). Infant mortality rates fell from 72 per 1000 live births in 19501955 to just 5 per 1000 live births in 2010-2015. From 1950 to 2015, Europe has become more urbanised. In the mid-twentieth century, around $52 \%$ of the total population in the region lived in urban settings, and by 2015 this had risen to $74 \%$, the expectation being around $82 \%$ in 2050 . According to the medium variant of the United Nations Population Forecasts, the population of Europe will decline in the coming years, falling to 716 million by 2050 , comprising $7 \%$ of total world population.

The final region of the world to be considered as far as growth and urbanisation are concerned is Oceania. In this region as a whole, population growth in the early 1950s was the second highest of the world's regions, amounting to $2.23 \%$ per annum. The region's growth rate then declined steadily to $1.35 \%$ per annum by the end of the twentieth century before increasing in the early years of the twenty-first century, standing at $1.54 \%$ in 2010-15 (United Nations 2017). Growth for the Oceania region is quite high as a region, driven by the combination of fertility and mortality levels (as well as international migration levels). Fertility levels remain relatively high by global comparisons. In the 1950s and 1960s total fertility was around 4 live births per female, inflated by levels of $5-8$ outside Australia and New Zealand. While levels of fertility in Australia and New Zealand have declined to below replacement level since then, elsewhere in the region fertility remains high, for example more than 4 live births per female in Samoa and the Solomon islands.

Population size of the region is extremely modest compared with the other major regions of the world. The relatively high levels of fertility have contributed to a tripling of population size from 13 million in 1950 to almost 40 million in 2015 (United Nations 2017). Declining mortality and increasing life expectancies have also been observed in Oceania since the middle of the twentieth century. In the early 1950s, life expectancy at birth for both sexes combined was 60.44 years, but the range across the region was significant, from 69 to 70 years in New Zealand and Australia to around 40 years in Papua New Guinea - one of the lowest in the world at the time outside subSaharan Africa. By 2010-15, the highest life expectancy was in Australia (82 years) and the lowest was still in Papua New Guinea, but here, life expectancy had reached 65 years in 2010-15. The global decline in infant mortality also occurred in Oceania with levels falling from 58 per 1000 live births in 1950-1955 to 21 per 1000 live births 
in 2010-2015. Once again, the difference between Australia and New Zealand on the one hand and the rest of the region on the other hand is striking. In 1950-55, infant mortality was around 25 per 100 live births in Australia and New Zealand compared with 170 in Vanuatu. And in 2010-15, the range is from 4 to 49 (in Papua New Guinea).

By 2015, the population of Oceania had reached almost 40 million and just $0.5 \%$ of global population, up from 13 million (still 0.5\%) in 1950. By 2050, population is expected to reach 57 million and $0.6 \%$ of world population. Urbanisation in the region is effectively limited to Australia and New Zealand, where in 1950 around $75 \%$ of the total populations lived in urban settings, and by 2015 this had risen to $88 \%$, the expectation being around $91 \%$ in 2050 - among the most urbanised countries of the world. However, elsewhere in the region, urbanisation is either (extremely) limited or extreme, which is simply a function of geography.

\section{Population Ageing}

The ageing of European populations began with the classic demographic transition characterised by a transition from high fertility and mortality to low fertility and mortality with mortality declining first of all leading to explosive population growth before fertility begins its continual decline leading to a slowing and eventual cessation of population growth (for example, Livi-Bacci 2012). This transition lasted for around 150 years giving societies and governments time to address and adjust as their populations transitioned from young to old. The infrastructures in place in the advanced economies of the world today such as long term care services, housing and transport, and pensions systems, have been developed accordingly in response to changing demographics and levels of welfare. More recently in the transitional economies of the world, this same demographic transition has got underway and is not only more dramatic in terms of scale, but also in terms of speed (for example, Khan and Leeson 2008). This leaves governments and societies in these economies with little time to address and adjust and their window of opportunity is closing slowly but surely. By the mid-twentieth century, population ageing was rooted in Europe and North America (Leeson 2009) while elsewhere youth still dominated the demographic stage. Even so, developments and levels of change differed across the regions of the world.

The populations of Europe and North America aged through the twentieth century and for these economies the future holds one of extremely low levels of fertility and radical life extension (Leeson 2015, 2016), while at the same time the populations of much of Asia will age on an unprecedented scale, driven primarily by rapidly declining fertility (Leeson 2014; Lutz et al. 2009). Fertility in the Republic of Korea, for example, has declined in the course of just one generation from 2.92 in 1975-80 to just 1.23 in 2010-15 (United Nations 2017). This presents challenges to individuals, families, and society as a whole, not least because many of these societies rely heavily on the family in respect of support for older people, while this traditional structures may be under pressure as the modern family changes (for example, Silverstein et al. 2006). The nuclear family is shrinking dramatically and the role of the family is changing likewise (Harper 2004).

As we move into the twenty-first century, the populations of Latin America and the Caribbean, with their own history, culture and traditions, will begin to mirror 
this ageing, and countries are variously prepared or unprepared to take on the challenge (Brea 2003). This will leave Africa as the final continent of youth - but for how long? In 2015, just 3.5\% of Africa's population of 1.2 billion were aged 65 years and over. By 2050, this will have increased to $6 \%$ of 2.5 billion, and by the end of the twenty-first century, the figures will have reached $14.6 \%$ of 4.5 billion. In the middle of the twentieth century, the regions of the world had youthful populations, with the proportion of population aged 65 years and over ranging from 3.2\% in Africa to 8.2\% in North America. Not until 1970 did we see any region, namely Europe, attain more than $10 \%$ of its population aged 65 years and over. In fact, North America (12.3\%) and Europe (14.7\%) were the only regions at the turn of the twenty-first century to have more than $10 \%$ of their populations aged 65 years and over. By 2015, Oceania (11.9\%) has joined the aged regions of the world, but elsewhere proportions aged 65 years and over remain below $10 \%$, with Africa having increased only modestly over 65 years to $3.5 \%$ of its population aged 65 years and over.

The next 35 years are predicted to witness dramatic increases in the number and proportion of older people in all regions of the world outside Africa. By 2050, almost $28 \%$ of Europe's population is expected to be aged 65 years and over, followed by North America (almost 23\%), Latin America (almost 20\%) and Asia (18\%). Africa will still have only $6 \%$ of its population aged over 65 years.

\section{Discussion}

Why then is age structural change so important? A recent report for the United Kingdom Government (Foresight 2016) discusses this in great detail, underlining the importance of a multi-pillared approach to tackling the issues raised by age structural change, ranging from pensions and health and social care to transport and housing, all of which to some degree will apply to all nations of the world as we move deeper into the twenty-first century. These demographic changes impact and will continue to impact across societies around the world. Growing old in societies dominated demographically by young people is fundamentally different from growing old in societies dominated demographically by older people. There are implications for individuals with respect to planning for old age; for families comprising more and more generations; for communities with increasing numbers of extreme aged people needing care and support; for workplaces short of younger skills. And governments will need to rethink how public services are planned and delivered across all government departments. These global age structural changes will everywhere require a co-ordinated response across government in order to reflect the inter-connectedness of policies affected by the ageing of populations.

Unless there are significant improvements in health as we move deeper into the twenty-first century, population ageing will increase the amount of ill-health and disability. Globally, chronic conditions, multi-morbidities, and cognitive impairments will become more common and in societies where the family plays a pivotal supporting and caring role, family members will at the same time face increasing pressure to balance this role with other work responsibilities. There is therefore a danger going forward that demand and supply of care will diverge, as more and more people need 
support (also financial support) while the pool of (younger) workers decreases and families feel the strain.

Population ageing brings with it an ageing workforce. In the more developed economies of the world, productivity and economic development will be increasingly linked to the ability to retain and reskill older workers. Retaining and reskilling older workers for longer will enable societies to support the increasing numbers of older dependents. At the same time, work beyond traditional retirement age will become an increasingly important pillar of financial security in old age. Radical changes to our workplace mentality will be fundamental to the economic wellbeing of societies and populations in the twenty-first century.

Lifelong learning, training and re-training will become important as populations age as this will allow us to remain active in the workplace and community, which in turn will enhance individual health and wellbeing. Our homes will play a major role in our future lives, and not just as places to live. Our homes will become places of work, play and care, and appropriately designed and adaptable housing will similarly enable us and contribute to our health and well-being as we age.

The question is whether population ageing is a particularly good or a particularly bad development. Causes for concern are linked to the ability of societal infrastructures to accommodate changes in age structures, in this instance the transition from a predominantly young world to a predominantly old world. Clearly, our definitions of old age and older people in a world where we are living longer and relatively healthy lives (for longer) needs revisiting. This applies most certainly to workplace perceptions and practices in respect of so-called older workers.

But ageing is an issue for individuals, families and communities as well as societies and governments to address and it is a question of whether individual and societal responses coincide or clash. Do individual aspirations to have fewer children and to live long, healthy lives clash with societal aspirations to drive growth? Should we dissuade medical science from finding the cure for diseases of old age, thereby reducing our longevity and life expectancy? Should we exempt couples with 3 or more children from paying income tax?

Add to the ageing of our populations, the urbanisation of our world outlined above and the issues for adaptation become even more complex (Harper 2016). As more and more of us live or aspire to live in urban communities, it is vital that these communities are managed and developed responsibly. Our urban communities are arguably important drivers of development as significant proportions of any nation's economic activity, government, business and trade, and transportation emanate from these communities. Those living in these communities potentially have access to better education, better health, and social services, and they have better and more opportunities for cultural and political participation. But for all these positive aspects of urbanisation, rapid and unplanned urban growth can be a threat to sustainable development. This happens when the necessary infrastructure is not developed or when the benefits of urban living are not distributed equitably across the tens of millions of citizens in these communities. Urban areas then become more unequal communities with millions of the urban poor living in unacceptable conditions.

Twenty-First century population development does indeed present both challenges and opportunities as discussed. 


\section{References}

Brea, J. A. (2003) Population Dynamics in Latin America, Population Bulletin, 58 (1), Population reference Bureau, Washington DC.

Foresight. (2016). Future of an ageing population. London: Government Office for Science.

Harper, S. (2004). Families in Ageing Societies: A Multi-Disciplinary Approach. Oxford: Oxford University Press.

Harper, S. (2016). How Population Change Will Transform our World. Oxford: Oxford University Press.

Khan, H., \& Leeson, G. W. (2008). The Demography of Aging in Bangladesh: A Scenario Analysis of the Consequences. Hallym International Journal of Aging, 8(1), 1-21.

Leeson, G.W. (2009) Demography, politics and policy in Europe, in Setting EU Priorities 2009 (ed. Ludlow, P), pp.102-124, The European Strategy Forum, Ponte de Lima.

Leeson, G. W. (2013). The demographics of ageing in Latin America, the Caribbean and the Iberian Peninsula, 1950-2050. In Envejecimiento -en America Latina y elCaribe (ed. Montes de Oca, V.) (pp. 53-71). Mexico: UNAM.

Leeson, G.W. (2014) Drivers of demographic change in the $20^{\text {th }}$ and $21^{\text {st }}$ centuries, in International Handbook on Ageing and Public Policy (eds. Harper, S. \& Hamblin, K.), pp. 23-35, Edward Elgar, Cheltenham.

Leeson, G.W. (2015) Understanding demographic change in Europe, in Bringing the burning issue of global demographic change to Europe's stages (eds. H. Wiley, E. Varenne \& P. Overmann), European Theatre Convention, Paris.

Leeson, G.W. (2016) The impact of mortality development on the number of centenarians in England and Wales, Journal of Population Research, Springer, 23 September 2016, pp. 1-15, doi https://oi. org/10.1007/s12546-016-9178-8.

Leeson, G.W. \& Harper, S. (2006) The Global Ageing Survey (GLAS) - Attitudes to ageing and later life, Oxford Institute of Ageing, Research Report 106, University of Oxford.

Leeson, G.W. \& Harper, S. (2007a) The Global Ageing Survey (GLAS) - Ageing and Later life, United Kingdom and Europe, Oxford Institute of Ageing, Research Report 107, University of Oxford.

Leeson, G.W. \& Harper, S. (2007b) The Global Ageing Survey (GLAS) - Ageing and Later life, The Americas, Oxford Institute of Ageing, Research Report 207, University of Oxford.

Leeson, G.W. \& Harper, S. (2007c) The Global Ageing Survey (GLAS) - Ageing and Later life, Hong Kong and Asia, Oxford Institute of Ageing, Research Report 307, University of Oxford.

Leeson, G.W. \& Harper, S. (2008) Some descriptive findings from the Global Ageing Survey (GLAS) Investing in Later Life, Oxford Institute of Ageing, Research Report 108, University of Oxford.

Livi-Bacci M. (2012) A concise history of world population, Wiley-Blackwell, Oxford \& Cambridge.

Lutz, W., Samir, K.C., Khan, H.T.A., Scherbov, S. \& Leeson, G.W. (2009) Future Ageing in Southeast Asia: demographic trends, human capital and health status, in Older Persons in Southeast Asia (eds. Evi Nurvidya \& Aris Ananta), pp. 47-67, Institute of Southeast Asian Studies (ISEAS), Singapore.

Silverstein, M. et al (2006) Intergenerational transfers and living arrangements of older people in rural China: Consequences for psychological well-being, The Journals of Gerontology Series B: Psychological Sciences and Social Sciences, 61 (5), pp. 256-266.

United Nations (2014) World Urbanization Prospects: 2014 Revision, Department of Economic and Social Affairs, Population Division, New York.

United Nations (2017) World Population Prospects: 2017 Revision, Department of Economic and Social Affairs, New York. 